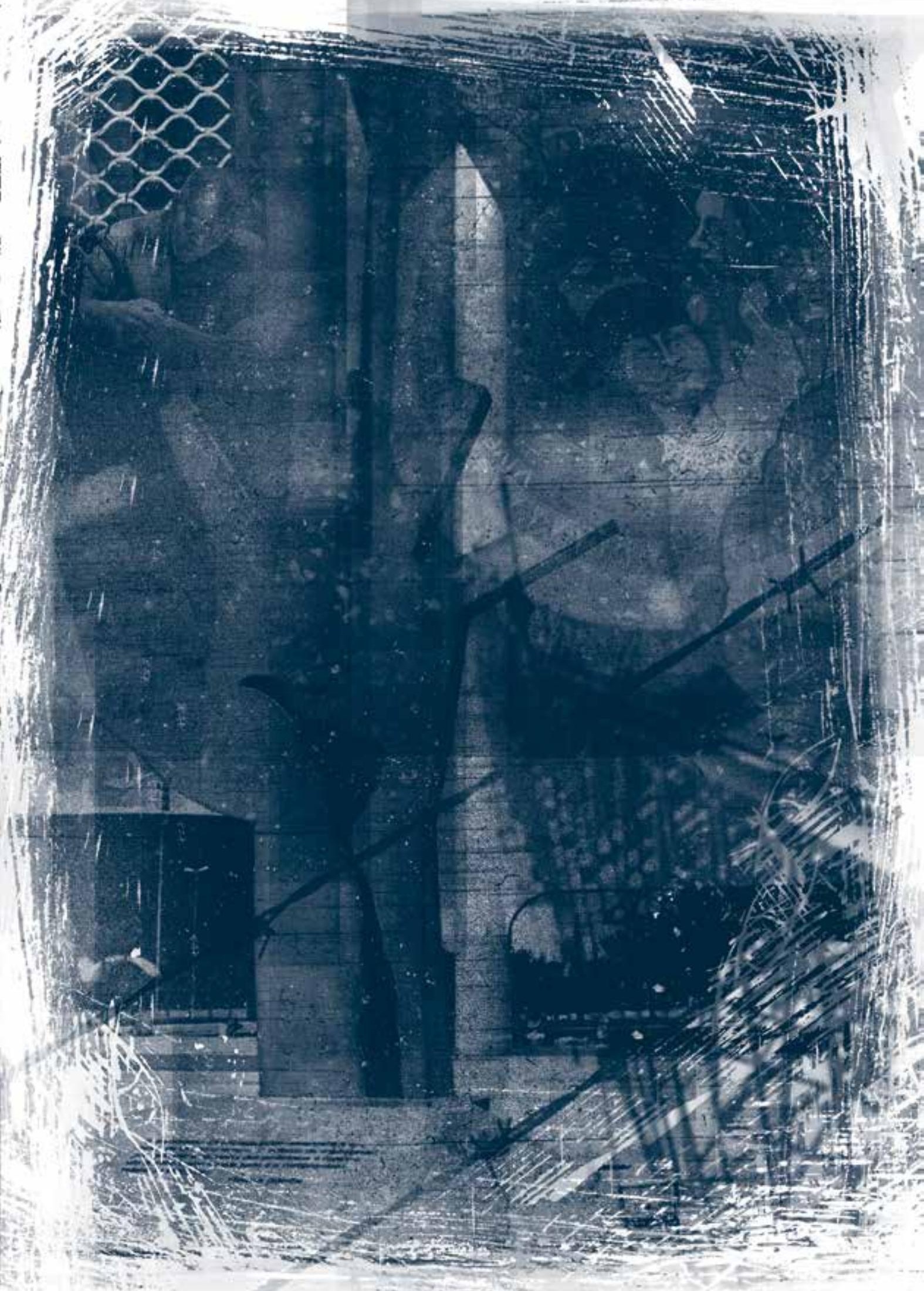




\title{
Pensar la Comunicación en Latinoamérica
}

Thinking communication in Latin America

DOI: 10.15213/redes.n10.p21

JESÚS MARTIN-BARBERO

\begin{abstract}
In order to balance the required size of this text with the history of hibridity and the density of the communication field in Latin America, mixing information, analysis and narrative is a must. Even more so when the writer of is not a distant observer, but someone involved in both the academic and research discussions introduced here, as well as in their social circumstances and political conditions. Especially when in the fifty years covered by the course of Latin American thought on communication, the field has undergone the greatest transformation in its history.
\end{abstract}

KEYWORDS: COMMUNICATION, ANALYSIS, HISTORY, LATIN AMERICA

RESUMEN

Conciliar el tamaño que debe tener este texto con la puesta en historia de los mestizajes y densidades de la formación del campo de la comunicación en Latinoamérica va exigir mezclar la información con el análisis y el relato. Ello con más razón cuando quien escribe este texto no es un observador distante sino alguien implicado tanto en los debates académicos e investigativos que aquí se exponen como en sus circunstancias sociales y sus condiciones políticas. Y aún más cuando en los cincuenta años que abarca el recorrido del pensamiento latinoamericano sobre el mundo de la comunicación este ha experimentado la mayor transformación de su historia.

PALABRAS CLAVE: COMUNICACIÓN, ANÁLISIS, HISTORIA, LATINO AMÉRICA

REDES.COM N ${ }^{\circ} 10 \mid 21$ 


\section{AÑos 60S/70s: LA CONSTRUCCIÓN DEL CAMPO DE ESTUdios}

La contrucción del campo de estudios de la comunicación se inicia en América Latina en los años sesenta amalgamando procesos e ideas propias gestadas en la "Teoria de la dependencia", con la formación académica tanto norteamericana como europea de varios investigadores, y a partir de un aglutinante decisivo: la voluntad de insertar los medios de comunicación en procesos de desarrollo social y democratización política de nuestros paises. Frente a la concepción funcional-difusionista propiciada por las agencias norteamericanas en esos años que, al identificar a los paises latinoamericanos como subdesarrollados, ligaba el "desarrollo" directamente al crecimiento cuantitativo del número de ejemplares de periódicos vendidos o de aparatos de radio y televisión por número de habitantes, la "teoria de la comunicación" que se gestaba desde estos paises proporcionó un enfoque histórico-social que hacía imposible desligar la acción de los medios de comunicación del contexto y los procesos políticos de la región. Lo que en últimas puso realmente en disputa la investigación latinoamericana en sus primeros años no fue el peso de los medios en la modernización de estos paises sino el sentido de la comunicación en la emancipación de nuestas sociedades. De ahí que la formación académica sobre comunicación naciera marcada por una doble función: estudiar la acción y conformación de los medios masivos, en su mayoria comerciales, buscando introducir en sus páginas y programas las voces de los actores sociales que estaban normalmente ausentes, y trabajando en la gestación de medios alternativos que en su misma con-formación resultaran democráticos.

El primer hito de esa "teoria propia" fue la idea de comunicación que Paulo Freire introdujo en el inicio mismo de los años 6os como ingrediente clave de un programa de educación de adultos, nacido el Nordeste brasileño con el nombre de "Educación liberadora". Alfabetizar será para el adulto poder apropiarse de su lengua, de tal manera que el escribir le posiblite "contar su propia historia", o sea comunicar, participar y decidir. La pedagogía de P. Freire (1963 y 1967) se inicia con la pregunta: ¿qué es un analfabeto?, a la que respondia diciendo: analfabeto es el hombre impedido de decir su palabra, impedido de ejercer de ciudadano. Para P. Freire, la lengua no está hecha sólo de sintaxis y semántica sino también de la pragmática, pues el lenguaje hace parte de la acción, incluye un "programa de acción, el proceso de liberación de la palabra propia. Pues la dominación que habita el lenguaje amordaza la acción y de ahí el gusto por la palabra hueca y la palabrería que no es sino la contracara del mutismo profundo que se expresa en la ausencia de participación de las mayorias en la vida social y política. 
Un segundo hito será la institucionalización del estudio de la comunicación y la investigación de los medios masivos en la Universidad Central de Venezuela llevada a cabo por Antonio Pasquali con la creación, el año 1974, del Instituto de Investigaciones de la Comunicación (ININCo) con Oswaldo Capriles, Elisabet Zafar,Luis Anibal Gomez; y del Proyecto Ratelve que inicia el estudio sobre políticas que aseguren espacios al servicio público de comunicación. De alguna manera tanto la institucionalización de los estudios como el proyecto de políticas públicas de comunicación se apoyanan un libro pionero publicado en 1970, Comprender la comunicación de A.Pasquali, y en el que de primera mano, llegaba a Latinoamerica la teoria crítica de la Escuela de Francfurt y el debate sobre las diferencias entre la comunicación y la información.

El tercer hito lo conforman un conjunto de voces e intituciones que van a insertar la teoria alternativa en investigaciones y propuestas políticas mediante la puesta en relación de la comunicación, la educación y desarro1lo. Las investigaciones van a des-cubrir la existencia de prácticas y experiencias pioneras en el uso educativo y social de un medio masivo, la radio, el más importante y característico en sociedades que eran aun culturalmente orales: Radio Sutatenza en Colombia, creada y actuada por una organización católica; las Radios mineras de Bolivia, creadas y regidas por los sindicatos mineros y apyadas organizaciones religiosas y educativas tras la nacionalización del estaño; en 1950 eran 33 las emisoras asociadas. Recogiendo explícitamente el legado de dos de sus profesores norteamericanos -Everett Rogers y Wilbur Schramm- un boliviano que conocia de cerca las experiencias colombiana y boliviana, Luis Ramiro Beltran, va a dinamizar una asociación informal con el paraguayo Diaz Bordenave, el brasileño Bosco Pinto y el uruguayo Mario Kaplun, el chileno Reyes Mata, para poner el discurso crítico en común y "en acción": en el año 1973 CiESPAL (Centro Internacional de Estudios Superiores de Periodismo) convoca en Costa Rica un primer Seminario sobre "La investigación de la Comunicación en América Latina" que sienta las bases para una investigación implicada en la creación de políticas nacionales de comunicación. Y el año 1976 se logra realizar, tambien en Costa Rica la Primera Conferencia Regional de Unesco en Políticas de Comunicación. En esa Conferencia se hará visible las experiencias a partir de las cuales los latinoamericanos - Antonio Paquali y Juan Somavía - tendran una decisiva participación en la elaboración del Informe MacBride (1978) sobre El nuevo orden mundial de la Comunicación y la Información (unEsCo, 1980).

En Chile y Argentina se configuró tambien un grupo de estudiosos e investigadores que marcará un hito: el que, juntando marxismo y semiología 
estructuralista con algunos elementos de la Teoria de la dependencia, elabora tanto una propuesta teórica como metodológica para el análisis ideológico de los mensajes en el medios masivos, que se aplicará especialmente a la prensa y la televisión. A la cabeza de ese grupo se hallaban Armand Mattelart desde Chile y Hector Schmucler desde Argentina, de cuya acción conjunta nacerá la primera revista con vocación latinoamericana: Comunicación y Cultura, cuyo subtítulo era La comunicación masiva en el proceso político latinoamericano. Contra la enorme dificultad que América Latina tenia entonces para la difusión y circulación de las revistas y los libros, Comunicación y cultura se volvió muy pronto el lugar de debates y "conversaciones" que implicaban a investigadores a todos nuestros paises. Y lo mismo sucedió con la gran circulación de los libros de A. Mattelart $(1970 ; 1973)$ y especialmente del que escriben A. Matellart y A. Dorfman Para leer al Pato Donald (1974) con prólogo de H, Schmucler.

Finalmente, el hito quizá más significativo de todos, la pronta gestación, en el año 1978, de ALAIC (Asociación Latinoamericana de Investigadores de Comunica- ción), y de felafacs (Federación Latinoamericana de Facultades de Comunicación Social) en 1981. Nacida entre Caracas y Lima, ALAIC amalgama múltiples actores y proyectos, diversos movimientos intelectuales y opciones políticas. Con ALAIC adquiere figura internacional el pensamiento latinoamericano tanto en términos de la investigación como de su representación en los diferentes foros mundiales como los convocados por AIERI-IAMCR, la UNESCO O IBERCOM. En la creación de ALAIC convergen necesidades "de comunicación" entre los diversos espacios regionales -andino, centroamérica, el cono sur- con el exilio que arranco de sus paises a muchos investigadores del sur llevándolos hacia México y centroamérica principalmente. Hay como un basculamiento desde el sur hacia México, país que tenia ya una larga experiencia de acoger exilados, de manera que ese país va a convertirse por una década en el polo de atracción de Instituciones Internacionales como el ILET (instituto latinoamericano de estudios transnacionales) o la FELAP (federación latinoamericana de periodistas) y tambien como nuevo lugar de dirección y publicación de revistas como Comunicación y cultura, o del ensanchamiento latinoamericano de editoriales como Siglo xxi. Muy pobre de recursos en sus comienzos ALAIC disfrutó de una gran imaginación para reunir a sus miembros incluyendo su presencia en muchos congresos y seminarios internacionales sobre otros temas, transportando en sus valijas de mano los libros escritos por sus miembros para que circularan por fuera del país en que fueron editados. Y promoviendo una primera colección de libros que recogieron el estado de la investigación por paises en Venezuela, Colombia, Perú, Chile y Argentina en un primer momento. 
FELAFACS nace en Lima en 1981 con el propósito renovar pofundamente la formación profesional/universitaria de los comunicadores, mediante la creación y el desarrollo de posgrados encaminados a la actualización de los docentes. Su pricipal campo de acción será promover la relación el intercambio de ideas y experiencias entre las asociaciones y facultades de comunicación social en América Latina y en otras regiones. FELAfAcs impulsará tanto el acompañamiento y apoyo a las experiencias académicas de formación de comunicadores que fueran ejemplos de renovación como a la creación de pensamiento propio através de revista DIA_LOGos de la Comunicación que ha llegado a su número 84.

A fines de la década de los 7os se inicia un desplazamiento del análisis de los medios hacia la comprensión de los procesos socioculturales. Y ello a partir de una complejización de los dispositivos del poder que devela y configura el pensamiento de M. Foucault: de meros aparatos de Estado, los medios pasan a verse mediados por procesos, prácticas y dispositivos de poder que desbordan la ideología, vinculando la función comunicativa de los medios con la gestión de los tiempos y de los cuerpos. El análisis de de los discursos no es ya el de unos instrumentos sino de aquello hace parte del cuerpo mismo del poder (J. Martin-Barbero, 1978).

\section{AÑ̃o 80S/90S: INVESTIGANDO LA COMUNICACIÓN DESDE LA(s) CULTURA(s)}

En los años ochenta la configuració de los estudios de comunicación muestra ya cambios de fondo, que provienen no sólo ni principalmente del interior propio de ese campo sino decambios en las ciencias sociales de Latinoamérica. Primero, los desplazamientos con que se buscará rehacer conceptual y metodológicamente el campo de la comunicación provendrán tanto de la experiencia de los movimientos sociales como de la reflexión que aportan los estudios culturales. Se inicia entonces un corrimiento de los linderos que demarcaban el campo de la comunicación: las fronteras, las vecindades y las topografias no son las mismas de hace apenas diez años ni están tan claras:desde la comunicación se comienzan a trabajar procesos y dimensiones que incorporan preguntas y saberes históricos, antropológicos, estéticos. Al mismo tiempo que la sociología, la antropología y la ciencia política empiezan a hacer cargo, ya no de forma marginal, de los medios y de los modos como operan las industrias culturales. De la sociología que investiga el lugar que ocupan los medios en las tranformaciones culturales a la tematización de los medios en los consumos y las políticas culturales. De la historia barrial de las culturas cotidianas en los sectores populares en el Buenos Aires de comienzos de siglo, a la historia de 
las tranformaciones sufridas por la música negra en Brasil en el recorrido que la lleva de las haciendas esclavistas a la ciudad masificada y su legitimación por la radio y el disco como música urbana y nacional. De la antropología que da cuenta de los cambios en el sistema de producción y en la economía simbólica de las artesanías a la que indaga permanencias y rupturas en los rituales urbanos del carnaval o en los juegos del alma y del cuerpo que encarnan las prácticas religiosas.O de las transformaciones de la comunicación en las grandes ciudades a las nuevas culturas urbanas de los jóvenes.

Hay un punto crucial del entrecuzamiento de los estudios de comunicación con la investigación social y cultural, se trata del seminario organizado por Clacso (Consejo Latinoamericano de Ciencias Sociales) en octubre '83, en Buenos Aires, coincidiendo con las primeras elecciones después del periodo trágico del régimen militar, y en el momento del regreso de un grupo grande de exiliados a la Argentina. Ese Seminario sobre comunicación y culturas populares constituirá un momento clave del diálogo y el debate de los estudiosos de la comunicación con histriadores, politólogos, analistas de los cambios culturales criticos de arte. $Y$ entre las muchas publicaciones que dan cuenta de lo que tuvo su punto de eclosión en aquel seminario citaremos cuatro libros cuyos títulos dan buena cuenta de lo que allí se fraguó: N. Garcia Canclini y R. Roncagliolo(eds.) 1988: Cultura trasnacional y cultural populares, IPAL, Lima; H. Herlinghaus y M. Walter, 1994: Posmodernidad en la periferia: enfoques latinoamericanos de la teoria cultural, Langer Verlag, Berlin; N.García Canclini, 1990: Culturas hỉbridas, Grijalbo, México; J. J. Brunner, 1992: América Latina: cultura $y$ modernidad, Grijalbo, México. Una dimensión estratégica de lo que ha cambiado se halla en la manera como lo que pasa en los medios es referido al complejo mundo de lo real social. Y de lo que es un claro ejemplo el estudio de la televisión ya no referido únicamente a su estructura comercial sino a lo que pone a ese medio en relación la vida pública: Oscar Landi (1992).

De otra parte la globalización larvada, aún con el nombre de trasnacionalización, hace visible el conflicto entre la carácter transnacional de la estructura económica y el carácter nacional de la esfera política. Una contradicción que aparece asociada a la recomposición de las fuerzas políticas políticas, y aun de los campos de lucha, pues dejan de estar tan nítidamente deslindados como unos años antes. $Y$ tomar conciencia de lo anterior significaba que la época de las 'grandes denuncias' - siempre necesarias - estaba dando paso a un trabajo más oscuro pero no menos arriesgado y dificil: la lucha contra la amalgama ecléctica que funcionalizaba la crítica y la lucha desde un neopositivismo-ambiente. Un neopositivismo que habia dejado de ser sólo de derechas y se hallaba tambien camuflado en el cierto pensamiento de izqquierdas, como el 
marxismo altuseriano, que seguia reduciendo los medios, y las «nuevas» tecnologías, a «aparatos ideológicos» de la clase dominante y del Estado. Lo que implicaba desconocer lo que en esas tecnologías - satélites, antenas parabólicas, interconexiones mediáticas - empazaba a configurarse : el estratégico paso del instrumental mediático a la configuración de un nuevo modelo de sociedad, y por tanto también de un nuevo entramado político-cultural. Pues solamente puestas en relación con el modelo de sociedad es que las nuevas tecnologías dejaban ver los cambios de fondo que con ellas se iniciaba. Stuart Hall (1981; 1984,) nos ayudó a comprender su verdadero alcance: «las comunicaciones están penetrando hasta el corazón del trabajo y del sistema productivo», y ello especialmente a través de «una idea de la información en cuanto materia prima de cualquier producción» con lo que «es todo el modelo democrático occidental el que está siendo afectado por la dirección en que marcha la sociedad informatizada». Y entonces fué la relación estratégica entre cultura e industria la que se emancipó del determinismo frankfurtiano gracias los análisis de S.Hall (1984) y de Murdok y P.Golding (1985) que comenzaron a descifrar la determinación social e ideológica ya no "en términos de contenidos sino de fijación de límites e imposición de demarcaciones”. Lo que hará posible investigar el otro sentido de las "estructuras de producción", esto es, en cuanto dispositivos de relación entre tecnologías, mercado y "rutinas productivas": códigos que, en cuanto sistema de operaciones tecno-discursivas, regulan el hacer del camarógrafo o el editor de TV, generando un saber que ellos adquieren ejerciendo su oficio y a través del cual se materializa un modo de ver y de contar lo que se ve. Ese nuevo horizonte del análisis fue retomado en Latinoamérica por el estudio de los usos sociales de unas tecnologías que, por primera vez no nos llegaban "de segunda mano", pero que las condiciones sociales en que vivian las mayorias les impedian acceder a ellas sin que en sus usos se introdujeran destiempo y anacrónias que hacían visible la heterogeneidad de nuestras culturas, y con ellas todo lo que un mero análisis ideológico de los contenidos no lograba pensar.

Pues más que una alternativa en si misma - fuente de idealizaciones y maniqueismos - lo que las prácticas de comunicación popular nos develaron fué el empobrecimiento radical que mercantalización de la vida social estaba produciendo sobre la comunicación cotidiana o festiva de las mayorias. Y frente al idealismo de una teoría de la diferencia, que colocaba las culturas indígenas en situación de exterioridad al desarrollo capitalista, y de una teoría de la resistencia que sobrevalora la capacidad de supervivencia cultural de las etnias, N. García Canclini (1982) propuso «un camino entre dos vértigos: ni las culturas indígenas pueden existir con la autonomía pretendida por ciertos 
antropólogos o folcloristas, ni son tampoco meros apéndices atípicos de un capitalismo que todo lo devora».

Se configuraba así un mapa nuevo: lejos de ser mera marginalidad, lo popular constituye un espacio social, económico y simbólico, en contínua lucha contra la entropía, a la vez que resulta estratégico para comprender la formación de las masas en la ciudad. Los modos populares de comunicación con la modernidad se covertian en claves de comprensión del mestizaje cultural en Latinoamérica. Pues el mestizaje no es cosa del pasado, aquel hecho racial del que vienen estos paises y pueblos, sino la trama de modernidades y discontinuidades culturales, de memoria largas e imaginarios efímeros que entrelazan lo indígena con lo rural y lo rural con lo urbano, el viejo folclor con las culturas populares y lo popular con la cultura masiva que representan los medios (J.Martin-Barbero, 1987).

Debemos a un conjunto de mujeres investigadoras el haber sabido poner en valor al medio más presente en la vida de la mayoria de la gente pero el más invisible para los investigadores, la radio, y desde lo que con ella hacen sus escuchas más que desde sus artimañas. Como si la "lectura de género", de la que tanto se habla hoy, hubiera comenzado en América Latina por un femenino modo de escuchar en la radio "el habla de las gentes del pueblo". En Argentina Patricia Terrero (1981) puso las bases a una historia de la radio teniendo como eje análisis de "los espacios de continuidad" entre tradiciones populares y cultura de masa, esto es la proximidad de ciertas expresiones del imaginario nacional y popular con procesos de mitificación y creencias populares que juegan un papel clave en la formación de la identidad social y cultural de los sectores populares. Desde la tradición de los payadores o copleros la radio recoge un largo proceso de sedimentación cultural que desembocará en el discurso populista, y con él en la conformación de las masas urbanas. En Chile, Giselle Munizaga y Paulina Gutiérrez (1983) indagan la especial capacidad de la radio para hacer el enlace de la racionalidad expresivo-simbólica popular y la modernizadora racionalidad informativo-instrumental. A través de la sonoridad - voz, música, efectos - que posibilita la superposición de tiempos y tareas y la "explotación" de la expresividad coloquial, la radio no sólo encauza sino que desencadena o impulsa un despliegue de una subjetividad que, al no encontrar cabida en la actividad política muy formalizada se desplaza hacia el mercado cultural. En Perú, los trabajos de Rosa María Alfaro (1987 y 1990) han trazado un mapa detallado de los modos en que la radio "capta" la densidad y la diversidad de condiciones de existencia de lo popular. La emisora popular urbana tiene un espacio propio pero bajo la dirección populista de otros sectores que lo 
cautelan desde fuera., pero au así el mundo popular se hace ahí presente bajo la identidad unificante de lo criollo: concursos en que se escenifica la pobreza y las ingeniosidades de la gente, un lenguaje que lleva a la radio la fonética, el vocabulario y la sintaxis de la calle y una presencia grande de la música en que se plasma hoy el mestizaje urbano en Lima: la "chicha". En Argentina tambien María Cristina Mata (1987 y 1988) realizó un profundo análisis de la cotidianidad construida desde el discurso radiofónico mediante los dispositivos con que ella se construye: primero la continuidad de la jornada, lograda mediante el enlace de unas voces que "leen" para su audiencia el acontecer diario; y segundo, continuidad en el tiempo de los locutores y los oyentes, una memoria que junta a los vecinos interpelados por la radio como integrantes de una comunidad barrial y unos usuarios y demandantes de servicios e instituciones públicas. Y en Brasil, Maria Immacolata Vasallo (1988) investigó las representaciones expresivas de los sectores populares en ciertos programas producidos por narradores que llevaban a la radio el lenguaje de la mayoria urbana viertiendolo en narrativas de corte policial o novela negra, en las que emergen situaciones y estilos de vida de las poblaciones más marginales, y que a su vez proceden del periodismo y la crónica roja.

El estudio de la televisión en América Latina tambien va a desbordar pronto el análisis de sus contenidos para insertarse en el estudio de su papel en las transformaciones de la vida urbana, pues paises que habia llegado a los años 60 s con la mayoria de su población en el campo vivian acelerados procesos de desplazamiento de las mayorias a las ciudades. Uno de los primeros estudiosos de esa relación entre cine, televisión y ciudad fue el mexicano Carlos Monsiváis (1988 y 1995) al dar visibilidad al juego cultural y comunicativo de las sensibilidades y sentimentalidades de las masas urbanas hecha con poeticas músicales desde la ranchera hasta el tango y con melodramas del cine y la televisión. Pues en pocos años el melodrama televisivo latinoamericano, la "telenovela", se convirtió no sólo en un fenómeno comercial fabuloso - especialmente en México y Brasil, Colombia y Venezuela - sino en una producción cultural cuyo éxito exigió una lectura en profundidad de los mestizajes narrativos, sociales y políticos que operan en la telenovela . Hay mucho más que dominación a analizar en un melodrama moderno hechgo de complicidades, resistencias e invenciones, de viejas moralidades familiares y nuevos contextos de conflictividad y rebeldias, de un denso re-conocimiento cultural de los humillados y excluidos cuya verdad constituye un profundo desafio a las estéticas de los eruditos y a las éticas intelectualizadas (Ortiz,R. 1989, Martín-Barbero y Muñoz,1992, M.I. Vasallo, 2002). 
La cuestión de las audiencias o de la recepción y el consumo de medios se va a convertir en un ámbito de investigación cada vez más densa desde comienzos de los 9os. Se trata de una investigación que rebasa los paradigmas tanto el de la transmisión como el de los efectos, exigiendo un acercamiento transdisciplinar capaz de asumir su envergadura histórica y antropológica. Desde el punto de vista conceptual lo que moviliza el estudio es el análisis de las mediaciones -socioeconómicas, políticulturales y técnicas- que regulan las formas del consumo y las modalidades de la recepción. Pues se trata de hacer emerger las figuras y el porqué del re-conocimiento que los públicos populares experimentan evidenciando un nosotros hasta ahora des-conocido por la investigación de la comunicación (G.Orozco, 1991, 1994; M. W. de Sousa, 1995; N.Jacks, 2011).

Y la otra línea de estudio en esos años fuéron las relaciones de la comunicación con la política, pasando del análisis de la política como contenido de los medios al nuevo lugar, estratégico, de la comunicación en los procesos y las prácticas políticas. Pioneros en ese campo fueron los estudio del argentino Nicolas Casullo (1985) al recolocar las cuestiones dee fondo: qué están significando para la política las transformaciones tecnológicas de los medios al fragmentar las audiencias y rehacer los modos de circulación de la información y de formación de la opinión pública. Desde el otro lado, el estallido brutal de una tubería que semidestruyó un barrio popular muy poblado de la ciudad de Gudalajara, en México, fue tomado por Rossana Reguillo (1996) para investigar desde abajo, desde la irrupción del miedo en la vida cotidiana miles de personas y la interrupción de todos los servicios públicos, tanto la movilización inmediata de la solidaridad entre los pobres como la tardía e incapaz participación de las instituciones públicas de la ciudad. Y mientras la desconfianza de la gente en la política se acrecienta crecen las figuras de protección basadas en la eficacia simbólica de los mitos y los rituales. Este último aspecto será retomado por la investigadora mexicana (2000) en una de las primeras investigaciones etnográficas sobre la formas de comunicación entre los jóvenes y de ellos con la sociedad; y unos años despues (2006) sobre las desubicaciones de la política ante las nuevas inseguridades sociales y las nuevas visibilidades ciudadanas. Desde Colombia, German Rey (1998) estudia las nuevas masmediaciones de la política: el nuevo lugar de los nuevos y las tecnologias al convertirse en escenarios cruciales de la vida pública. De un lado se trata de investigar la reconfiguración conceptual de "lo público" como "lo comun a todos, en cuanto difundido, hecho público" proveniente de H.Arendt y R. Sennet, y a su vez las relaciones entre el interés común, el espacio ciudadano y la intreacción comunicativa. Lo que se traduce en el reconocimiento 
de nuevos derechos de los ciudadanos: a ser informados pero tambien poder informar, a ser escuchados y poder hablar, a hacerse visibles en toda la gama de las desgualdades sociales y las diversidades culturales. Unos años despues (2009) lo que marca la agenda de investigación será la nueva complejidad de las políticas públicas en el cruce de la comuncaciones con las nuevas culturas.

\section{CAMBIO DE SIGLO: GLOBALIzACIÓN Y MUTACIÓN TECNOCULTURAL DE LA COMUNicación}

La globalización no es un puro avatar de la economía y el mercado sino un movimiento que, al hacer de la comunicación y la información la clave de un nuevo modelo de sociedad, empuja todas las sociedades hacia una intensificación de sus contactos y sus conflictos, exponiendo todas las culturas unas a otras como jamás antes lo estuvieron. De ahí que la ubicación del estudio de la comunicación en los nuevos escenarios esté implicando desconcertantes desafios, como el que entraña pensar el denso espesor sociocultural de la mediación tecnológica no solo de la comunicación sino de la producción e incluso de la sociedad en su conjunto. Pues las tranformaciones de la tecnología remiten hoy más que a la novedad de unos aparatos a nuevos modos de percepción y de lenguaje, a nuevas sensibilidades y escrituras. Estamos ante una mutación cultural que implica la asociación del nuevo modo de producir con un nuevo modo de comunicar que convierte al conocimiento en fuerza productiva directa. Lo que en el-mundo-de-la comunicación cambia hoy es haberse convertido en el eje de una mutación tecnocultural que afecta a nuestras sociedades desde dentro y por entero. Pero como repite una y otra vez Manuel Castells $(1997,31-32)$ "la tecnología no determina a la sociedad: la plasma. Y plasma especialmente su capacidad de transformarse. La tecnología es sociedad y ésta no puede ser comprendida o representada sin sus herramientas técnicas.".

Lo que la comunicación nos está exigiendo pensar es la hegemonía de una razon comunicacional cuyos dispositivos -la fragmentación que disloca y descentra, el flujo que globaliza y comprime, la conexión que desmaterializa e hibrida- agencian el devenir mercado de la sociedad. Y lo que desde Latinoamérica se buscando pensar es justamente la hegemonia comunicacional del mercado en la sociedad: la comunicación convertida en el más eficaz motor del desenganche e inserción de las culturas - étnicas, nacionales o locales - en el espacio/tiempo del mercado. En el mismo sentido estamos necesitando pensar el lugar estratégico que ha pasado a ocupar la comunicación en la configuración de los nuevos modelos de sociedad. 
Ello está exigiéndonos distinguir dos proyectos muy diferentes. Uno que, partiendo de la envergadura económico-cultural que han adquirido las tecnologías audiovisuales e informáticas en los acelerados procesos de globalización, busca hacerse cargo de las tecnologías a la hora de construir políticas culturales que hagan frente a los efectos desocializadores del neoliberalismo e inserten explícitamente las industras culturales en la construción económica y política de la region. El otro resulta de la combinación del optimismo tecnológico con el más radical pesimismo político, y lo que busca es legitimar, tras el poder de las tecnologías, la omnipresencia mediadora del mercado. Pervirtiendo el sentido de las demandas políticas y culturales, que encuentran de algun modo expresión en las tranformaciones tecnológicas, se deslegitima cualquier cuestionamiento de un orden social al que sólo el mercado y las tecnologías permitirían darse forma. Pero, ¿cómo asumir entonces el espesor social y perceptivo que hoy revisten las tecnologias comunicacionales, sus modos transversales de presencia en la cotidianidad desde el trabajo al juego, sus espesas formas de mediación tanto del conocimiento como de la política, sin ceder al realismo de lo inevitable que produce la fascinación tecnológica, y su complicidad neoliberal con el mercado como único principio organizador de la sociedad en su conjunto?.

Desde la sociologia de la cultura, Renato Ortiz (1994 y 2006) introduce la necesidad de diferenciar las lógicas unificantes de la globlalización económica de las que mundializan la cultura. Pues la mundialización cultural no opera desde un afuera sobre esferas dotadas de autónomia como lo nacional o lo local. La mundialización es un proceso que se hace y deshace incesantemente. Y ello hace imposible hablar de una cultura-mundo que se situaria por encima de las culturas nacionales o locales.La mundialización no puede confundirse con la estandarización de los diferentes ámbitos de la vida que fué lo que produjo la industrialización, incluido el ámbito de la cultura, esa "industria cultural" que fué el objeto de análisis de la Escuela de Frankfurt. Ahora nos encontramos ante otro tipo de proceso, que se expresa en una cultura de la modernidad-mundo, que es una nueva manera de estar en el mundo. De la que hablan los hondos cambios producidos en el mundo de la vida: en el trabajo, la pareja, la comida, el ocio. Es porque la jornada contínua ha hecho imposible para millones de personas almorzar en casa, y porque cada dia más mujeres trabajan fuera ella, y porque los hijos se autonomizan de los padres muy tempranamente, y porque la figura patriarcal se ha devaluado tanto como se ha valorizado el trabajo de la mujer, que la comida ha dejado de ser un ritual que congrega a la familia. Y desimbolizada, la comida diaria ha encontrado su forma en el fast-food. De ahí que el éxito de McDonald's 
o de las pizzas Hut hable menos de la imposición de la comida norteamericana que de los profundos cambios en la vida cotidiana de la gente, cambios que esos productos sin duda expresan y rentabilizan. Pues desincronizada de los tiempos rituales de antaño y de los lugares que simbolizaban la convocatoria familiar y el respeto a la autoridad patriarcal, los nuevos modos y productos de la alimentación "pierden la rigidez de los territorios y las costumbres convirtiéndose en informaciones ajustadas a la polisemia de los contextos". Reconocer eso no significa desconocer la creciente monopolización de la distribución, o la descentralización que concentra poder y el desarraigo empujando la hibridación de las culturas. Ligados estructuralmente a la globalización económica pero sin agotarse en ella, se producen fenómenos de mundialización de imaginarios ligados a músicas, a imágenes y personajes que representan estilos y valores desterritorializados y a los que corresponden tambien nueva figuras de la memoria.

Desde la geografía política, Milton Santos, ya en 1996, planteó como la ausencia de categorías analíticas mantiene a las ciencias sociales ancladas en el eje del Estado-nación cuando lo que estamos necesitando pensar ahora es el mundo, esto es el paso de la internacionalización a la mundialización. Y no porque esa categoria y esa sociedad no sigan teniendo vigencia -la expansión y exasperación de los nacionalismos de toda laya asi lo atestigua- sino porque el conocimiento acumulado sobre lo nacional responde a un paradigma que no puede ya dar cuenta ni histórica ni teóricamente de toda la realidad en la que se insertan hoy individuos y clases, naciones y nacionalidades, culturas y civilizaciones. Y en su último libro publicado en vida, el año 2004, su pensamiento expone una desafiante visión de la globalización a la vez como perversidad y como posibilidad: esa paradoja cuyo vértigo amanaza con paralizar tanto el pensamiento como la acción capaz de tranformar su curso. Pues de un lado la globalización fabula el proceso avasallador del mercado, un proceso que al mismo tiempo que uniforma el planeta profundiza las desigualdades pues lo des-une cada dia más. De ahí la perversidad sistémica que implica y produce el aumento de la probreza y la desigualdad, del desempleo tornado ya crónico, de enfermedades que, como el sida, se tornán epidemia devastadora en los continentes no más pobres sino más saqueados. Pero la globlización representa tambien un conjunto extraordinario de posibilidades, cambios ahora posibles que se apoyan en hechos radicalmente nuevos entre los que sobresalen dos: uno, la enorme y densa mezcla de pueblos, razas, culturas y gustos que se producen hoy - aunque con grandes diferencias y asimestrias - en todos los continentes, una mezcla posible sólo en la medida en que emergen con mucha fuerza cosmovisiones otras que ponen en crisis 
la hegemonia del racionalismo occidental; y el otro, unas nuevas tecnologías que estan siendo crecientemente apropiadas por grupos de los sectores subalternos posibilitandoles una verdera "revancha sociocultural", esto es la construcción de una contrahegemonia a lo largo y ancho del mundo. Ese conjunto de posibilidades abren la humanidad por primera vez en la historia a una "universalidad empírica" y de ahí a una nueva narrativa histórica. Pero la construcción de esa narrativa pasa por una "mutación política", un nuevo tipo de utopia capaz de asumir la envergadura de los siguientes desafios:

- La existencia de un nuevo sistema técnico a escala planetaria que transforma el uso del tiempo al producir la convergencia y simultaneidad de los momentos en todo el mundo.

- El atraviesamiento de las viejas tecnologias por las nuevas llevándonos de una influencia puntual - por efectos de cada técnica aisladamente como lo fue hasta ahora- a una conexión e influencia transversal que afecta directa o indirectamente al conjunto de cada país.

- Lo que implica la actual mediación de la política, pues si la producción se fragmenta como nunca antes por medio de la técnica, nunca fue más fuerte la unidad política que articula las fases y comanda el conjunto a través de una poderosa "unidad de motor" que deja atrás la pluralidad de motores y ritmos con los que trabajaba el viejo imperialismo. El nuevo tipo de motor que mueve la globalización es la "competitivida exponencial" entre empresas de todo el mundo "exigiendo cada dia más ciencia, más tecnología y mejor organización”.

- La peculiaridad de la crisis que atraviesa el capitalismo reside entonces en el entrechoque continuo de los factores de cambio que ahora rebasan las viejas gradaciones y mensurabilidades desbordando territorios, paises y continentes.

- Ese entrechoque, hecho de una extrema movilidad de las relaciones y una gran adaptabilidad de los actores reintroduce "la centralidad de la periferia", no sólo en el plano de los paises sino de lo social marginado por la economia y ahora recentrado como "la nueva base en la afirmación del reino de la política". 
Desde la antropología y la crítica cultural N. Garcia Canclini inicia (1999) una propuesta de agenda sobre la interculturalidad, pues ella nombra tanto la densidad de los conflictos sociales como la densidad de los intercambios que viven las étnias, las regiones y las naciones; y nombra tambien el lugar epistémico desde el que abarcar conflictos e intercambios comprensivamente, que continurá (2006) enfrentando las polémicas y los malentendidos que se producen cuando se pretenden solucionar las indiluibles desigualdades sociales con la sola defensa de la diferencia cultural, y tambien cuando se pretende explicar desde el ámbito socioeconómico la densidad simbolica de los problemas y los derechos culturales. Lo que le exigirá una puesta de lo latinoamericano en el mundo, (2002) ligando explícitamente la cuestión de la globalización a la pregunta que mira tanto hacia las transformaciones del mundo como a las inercias mentales que arrastran aún la visión folclórica o su contraria la de un pesismismo determinista.

Entonces, tanto o más que objetos de políticas, las tecnologias de la comunicación, la información y la cultura constituyen hoy un campo primordial de batalla política: el estratégico escenario que le exige a la política recuperar su dimensión simbólica -su capacidad de representar el vínculo entre los ciudadanos, el sentimiento de pertenencia a una comunidad- para enfrentar la erosión del orden colectivo. Que es lo que no puede hacer el mercado por más eficaz que sea su simulacro.

Al llegar al balace final de este mapa trazado a mano alzada debo dejar constancia de tres nombres que escapan tanto a las cronologias como a las temáticas. Eliseo Veron, que fue el pionero en el análisis complejo de los discursos medáticos y en hacer emerger la figura del sujeto/receptor activo en el proceso de comunicación $((1969,1988)$ hasta sus últimos trabajos sobre la cultura visual y el concepto de agenda (2002). Anibal Ford, proveniente del mundo de la producción editorial y periodista, entra en el estudio de la comunicación a mediados de los 80 con su libro sobre culturas populares (1985) para ponerlas después en relación con las culturas y las narrativas electrónicas desde un análisis que entrelaza la estética con la política (1994) y culmina en un estudio fuertemnente crítico de la globalización (1999) cuyo título suena a apocalíptico sin que el libro lo sea. Y José Marquez de Melo, investigador y hombre de acción, fundo y presidió INTERCOM, la Sociedad Brasilera de Estudos da Comunicacao, ha sido el presidente más duradero de AlAIC, y gestiona un centro de estudios dedicado a valorar el pensamiento latinoamericano en Comunicación; de ahí que desde sus comienzos (1974) hasta su más reciente publicación (2008) los paradigmas propios de la investigación latinoamericana, y sus limitaciones, hayan sido su tema y su obsesión. 


\section{BIBLIOGRAFía}

1. AÑos 6os/70s: LA CONSTRUCCIÓN DEL CAMPO DE ESTUDIOS

BELTRÁN, L.R. (1976). La investigación en comunicación en Latinoamérica: ¿indagación con anteojeras?. Caracas: Mimeo.

BELTRÁN, L.R. (1976). Premisas, objetos y métodos foráneos en la investigación sobre comunicación en Latinoamérica, en Chasqui, N1. Quito.

FREIRE, P. (1963). Alfabetização e conscientização. Porto Alegre: Editora Emma. FREIRE, P. (1967). Educação como prática da liberdade. São Paulo: Paz e Terra.

MARTIN-BARBERO, J. (1978). Comunicación masiva, discurso y poder. Quito: Ciespal.

KAPLUN, M. (1973). La comunicación de masas en América Latina, Montevideo: Ediciones Paulinas.

KAPLUN, M. (1988). Una pedagogía de la comunicación, Madrid: Ed. La Torre. MacBRIDE, S./UNESCO (1980). Un solo mundo,voces multiples: comunicación e información en nuestro tiempo, México: FCE.

MATTELART, A. (1970) La ideología de la dominación en una sociedad dependiente. Buenos Aires: Signos.

MATTELART, A. (1973). La comunicación masiva en el proceso de liberación. Buenos Aires: Siglo XXI.

MATTElART, A.; DORFMAN, A. (1974). Para leer al Pato Donald. Buenos Aires: Siglo XXI.

PASQUALI, A. (1970). Comprender la comunicación. Caracas: Monte Avila.

2. AÑos 80S/90S: INVESTIGANDO LA COMUNICACIÓN DESDE LA(s) CULTURA(s)

ALFARO, R.Ma. (1987). De la conquista de la ciudad a la apropiación de la palabra. Lima: Tarea.

ALFARO, R.Ma. (1990). Cultura de masas y cultura popular en la radio peruana. Lima: Calandria/Tarea.

BRUNNER, J.J.; CATALÁN, C.C.A. (1989). Chile: transformaciones culturales y conflictos de la modernidad. Santiago: Flacso.

BRUNNER, J.J. (1992). América Latina: cultura y modernidad. México: Grijalbo.

CASULLO, N. (EDIT) (1985). Comunicación: la democracia deficil. Buenos Aires: iLET.Folios.

Da MATTA, R. (1981). Carnavais, malandros, heróis. Rio de Janeiro: Zahar.

De SOUSA, M.W. (oRG) (1995). Sujeito, o lado escuro do receptor. São Paulo: Brasiliense. 
GOLDING, P. (1985) Capitalismo, comunicaciones y relaciones de clase en MURDOCK, G.; GOLDING; P., en Sociedad y comunicación de masas. México: F.C.E.

CANCLINI, N.G. (1982). Las culturas populares en el capitalismo. México: Nueva Imagen.

CANCLINI, N.G. (1990). Culturas híbridas. México: Grijalbo.

CANCLINI, N.G. (1994) (edit.). Políticas culturales en América Latina. México: Grijalbo.

CANCLINI, N.G.; RONCAGLIOLO, R. (EDs.) (1988). Cultura trasnacional y cultural populares. Lima: IPAL.

GUTIEREZ, L.; ROMERO, L.A. (1985). Sectores populares y cultura política. Buenos Aires: Sudamericana.

HERLINGHAUS, H.; WALTER, M. (1994). Posmodernidad en la periferia: enfoques latinoamericanos de la teoria cultural. Berlin: Langer Verlag.

HALL, S. (1981). La cultura, los medios de comunicación: el efecto ideológico, en CURRAN, J.; GUREVITC, M.; WOOLLACOTT, J. Sociedad y comunicación de masas. México: F.C.E.

HALL, S. (1984). Estudios culturales: dos paradigmas, rev. Hueso $\mathbf{N}^{0}$. 19. Lima.

LANDI, O. (1992). Devórame otra vez: qué hizo la televisión con la gente, qué hace la gente con la televisión. Buenos Aires: Planeta.

JACKS, N. (COORD.). Análisis de la recepción en América Latina. Quito: Ciespal.

MARTIN-BARBERO, J. (1987). De los medios a las mediaciones. Barcelona: Gustavo Gili.

MARTIN-BARBERO, J.; MUÑOZ, S. (1992). Televisión y melodrama. Bogotá: Tercer Mundo.

MARTIN-BARBERO, J.; REY, G. (1999). Los ejercicios del ver. Barcelona: Gedisa.

MATA, Ma.C. (1987). Cuando la comunicación puede ser sentida como propia, una experiencia de radio popular, en Comunicación y culturas populares. México: Gustavo Gili.

MATA, Ma.C. (1988). Radios y públicos populares, en Dia-logos de la comunicación, $\mathbf{N}^{\circ}$. 19, Lima.

MONSIVÁIS, C. (1988). Escenas de pudor y liviandad. México: Grijalbo.

MONSIVÁIS, C. (1995). Los rituales del caos. México: Ediciones Era.

OROZCO, G. (1991). Recepción televisiva. Tres aproximaciones para su estudio. México: Univ. Iberoaméricana.

OROZCO, G. (1994). Televidencia. Perspectivas para el análisis de la recepción televisiva. México: Univ. Iberoaméricana.

ORTIZ, R. (COORD.) (1989). Telenovela: história e produção. São Paulo: Brasiliense. 
REGUILLO, R. (1996). La construcción simbólica de la ciudad: sociedad, desastre, comunicación. Guadalajara: Iteso.

REGUILLO, R. (2000). Estrategias del desencanto. Emergencia de culturas juveniles. Buenos Aires: Norma.

REY, G. (1998). Balsas y medusas: visibilidad comunicativa y narrativas politicas. Bogotá: Fescol.

REY, G. (2009). Industrias culturales. creatividad y desarrollo. Madrid: AECI.

SQUEF, E.; WISNIK, J.M. (1983). O nacional e o popular na cultura brasileira: música. São Paulo: Brasiliense.

SODRÉ, M.(1983). A verdade seducida. Por un conceito de cultura no Brasil. Rio de Janeiro: Codecrí.

TERRERO, P. (1981). El radioteatro. Buenos Aires: C.E. de A.L.

VASSALLO, M.I. (1988). La radio de los pobres: estudio de comunicación de masas, ideología y marginalidad social. São Paulo: Edições Loyola.

VASSALLO, M.I. (COORd.) (2002). Vivendo com a Telenovela. São Paulo: Summus.

VV.AA. (1987). Comunicación y culturas populares en Latinoamérica. México: G.Gili.

3. CAMBIO DE SIGLO: GLOBALIZACIÓN Y MUTACIÓN TECNOCULTURAL DE LA COMUNICACIÓN

CASTELLS, M. (1997). La sociedad red, vol.1 de La era de la Información. Madrid: Alianza.

FORD, A. (1985). Medios de comunicación y cultura popular. Buenos Aires: Legasa.

FORD, A. (1994). Navegaciones: comunicación, cultura y crisis. Buenos Aires: Amorrurtu.

FORD, A. (1999). La marca de la bestia: identificación, desigualdades e infoentretenimiento en la sociedad contemporánea. Buenos Aires: Norma.

CANCLINI, N.G. (1999). La globalización imaginada. Barcelona: Paidós.

CANCLINI, N.G. (2002). Latinoamericanos buscando lugar en este siglo. Buenos Aires: Paidos.

CANCLINI, N.G. (2006). Diferentes, desiguales y desconectados. Barcelona: Gedisa.

De MELLO, J.M. (1974). Comunicação social: teoria e pesquisa. Petrópolis: Vozes.

De MELLO, J.M. (1998). Teoria de la comunicaçao: paradigmas latino-americanos. Petrópolis: Vozes. 
De MEllo, J.M. (2008). História Política das Ciências da Comunicação. Rio de Janeiro: Editora Mauad X.

ORTIZ, R. (1994). Mundialização e cultura. São Paulo: Brasiliense.

ORTIZ, R. (2006) Mundialização: saberes e crencas. São Paulo: Brasiliense.

SANTOS, M. (1996). A natureza do espaço. São Paulo: Hucitec.

SANTOS, M. (2004). Por otra globalización. Bogotá: CAB.

VERON, E. (1969). Ideología y comunicación de masas. Buenos Aires: Nueva Visión.

VERON, E. (1988). La semiosis social. Barcelona: Gedisa.

VERON, E. (2002). Espacios mentales: Efectos de agenda 2. Barcelona: Gedisa. 